\title{
Distribution of biomarkers of aging in people with different personality types (in Russia)
}

\author{
Tatiana Berezina ${ }^{1, *}$ \\ ${ }^{1}$ Moscow State University of Psychology and Education, Moscow, Russia
}

\begin{abstract}
The aim of the research is to study how a person's belonging to a certain type of personality (phenotypic, professional, emotional, communicative) influences the rate of his individual aging. Method: we used the Russian frailty index according to Dr. Voitenko, which includes subjective and objective biomarkers of aging: duration of static balancing, blood pressure indicators, body weight, subjective assessment of diseases. Data processing method - one-way analysis of variance (ANOVA). Empirical base: 987 people (including 575 women) aged 35-70 years, collected from different regions of Russia on a territorial basis. Results: in the professional sphere, the lowest frailty index was found in representatives of the Artistic type and Investigative type of professions, and in terms of the duration of static balancing, the best result was in the Enterprising type. In terms of phenotypic characteristics, representatives of the asthenic and athletic body types had a lower frailty index, and in terms of functional asymmetry - in ambidexters and retrained left-handers. Among the emotional types, the lower frailty index was observed in persons with a predominance of communicative emotionality and those who preferred the style of cooperation when interacting with other people. Conclusions: lifestyle, attitude to the world and other people, as well as phenotypic characteristics of a person affect his biological age and the intensity of his biomarkers of aging.
\end{abstract}

\section{Introduction}

The problem of isolating biomarkers of aging has acquired particular urgency over the past decades. This is caused by an increase in life expectancy and an increase in the retirement age in many countries. All this brings to the fore the problem of diagnosing, maintaining and supporting healthy aging. The development of a system of reliable biomarkers of aging is mainly aimed at diagnostics, but in a way that it would be useful for the purposes of predicting a person's condition, the duration of his potential working period, as well as for assessing the effectiveness of psychological support for healthy aging. Since the dynamics of biomarkers of healthy aging depends on a person's previous life path, the level of his education, food preferences [1], it may also be associated with his individual typological characteristics. Since many of these features are amenable to conscious control and can be arbitrarily

\footnotetext{
* Corresponding author: tanberez@list.ru
} 
changed, the identification of such regularities enhances the relevance of the study in terms of the possibility of using them to maintain healthy aging and antiaging.

\section{Literature review}

Since individuals of the same age have different aging rates, quantitative biomarkers of aging are valuable tools for measuring physiological age, assessing the degree of "healthy aging", and potentially predicting the duration of health and human life expectancy [2]. At the same time, the rate of aging depends not only on hereditary predisposition, but also on the factors of a person's individual organization of his life path [3]. It has been shown that education, the characteristics of a person's life path and the choice of a particular way of life affect the brain's ability to respond to nervous disorders associated with aging and compensate them, slowing down the relative biological aging of the nervous system [4].

There is a fairly large number of biomarkers of aging, which are used in various studies for various purposes [5], [6]. In a recent review of works, it is noted that the isolated biomarkers of aging (BoA) should predict the functional capabilities of the organism at a later age [7]. The American Federation for Aging Research (AFAR) has proposed the following criteria for biomarkers of aging: the criterion of simplicity: it should be able to be retested without harm to humans (for example, a blood test or imaging method), another criterion is predictiveness - it should predict the rate of aging (i.e. precisely determine at what stage of life a person is now), and they should give a more accurate forecast of life expectancy than chronological age [8].

Despite the fact that most of the biomarkers relate to molecular biological or clinical indicators, some of them, which are easy to measure, can be used in psychobiological research. These include, for example, phenotypic biomarkers of aging. In this regard, the following indicators are most commonly used: walking speed, body position, standing balance, grip strength, body mass index, waist circumference, and muscle mass [9]. Also noteworthy is the British panel of biomarkers of healthy aging developed by José Lara and co-authors [8]. It includes not only biological and phenotypic characteristics, but also indicators of physical performance, i.e. a person's ability to perform physical tasks in everyday life, as well as measuring the level of preservation of cognitive functions.

The relationship of some biomarkers of aging with individual-typological personality traits has also been studied. A large number of studies are devoted to the study of the relationship between the dynamics of biomarkers of healthy aging with the professional characteristics of a person. The most famous is the study of two types of behavior by $\mathrm{M}$. Friedman and R. Rosenman: type A - "fight or flight", type B behavior - "hiding". Type A behavior correlates with the risk of cardiovascular disease (one of the biomarkers of aging) and is presented in men and women engaged in competitive activities (business, management), the data have been confirmed in modern studies, where it was emphasized that a marker of aging is precisely the level of hostility inherent in type A behavior [10].

The nature of the professional activity performed is also a factor influencing the development of cardiovascular diseases. The main types of activity, which are factors in the development of diseases of the cardiovascular system, are highlighted. The first is the "demand-control" working stress model (by R. Karasek). Within the framework of this model, the most unfavorable for the cardiovascular system is work that requires a lot of performance, and at the same time, it is characterized by a low level of decision-making [11]. The second is the "effort-reward" imbalance model (by J. Siegrist). According to this approach, the most dangerous work for the development of cardiovascular diseases and atherosclerosis is work that requires more output, but does not give a decent reward [12]. Summarizing the above, the authors emphasize the importance of the occupational type as a factor influencing the development and course of diseases of the cardiovascular system [13]. 
In addition to cardiovascular diseases, studies of the influence of the occupational type on another biomarker of aging - the work of the system of balance organs and the musculoskeletal system - are also known. A study of Finnish municipal workers [14] revealed that in men, retirement leads to an increase in morbidity associated with disorders of the musculoskeletal system (39-58\% versus $25-37 \%$ among those who continue to work). The authors especially noted that the likelihood of developing diseases in mental workers is higher than in physical workers, and in men it is higher than in women.

But other authors claim that belonging to the professional type affects the Frailty Index. In representatives of the intellectual type of profession, it is lower, the indicators of selfesteem of health, work of the cardiovascular system and the system of balance organs are better [15].

The relationship between professional types and life expectancy is also known. A recent review of 17 studies (with 193,696 participants from different countries, mainly the European Union) found that men working in the field of mental work and other forms of cognitive employment had an $18 \%$ lower risk of early mortality compared with those who were engaged mainly in manual labor [16]. High social status, leadership work, career growth are factors that increase life expectancy [17]. It was shown that the lowest probability of premature death is for top-level administrators, for other managers and qualified specialists it is 1.6 times higher, for office workers - 2.2 times, and for workers - 2.7 times [18].

Most of the elementary biomarkers of aging are combined into an integral indicator - the Frailty Index [19]. There are many options for calculating the F-Index, most of which are based on determining from 1 to 5 key indicators that determine the phenotype of frailty: slowness, weakness, low physical activity, exhaustion, weight loss, as well as indicators of cardiovascular and respiratory systems. The Russian analogue of the Frailty Index is called "biological age" [20]. There are also a large number of options for calculating biological age, but almost all options include indicators of the cardiovascular system, respiratory system, body weight, static balancing, self-assessment of health [21].

In Russia, a significant number of studies have been carried out on the distribution of indicators of biological age in various occupational types. For example, it has been shown that the biological age of representatives of mental labor is lower than that of representatives of manual labor who have the same calendar age, i.e., according to biomarkers, workers of an intellectual type of profession are younger. It is also shown that the biological age of unemployed people increases in relation to the expected biological age and in relation to the calendar age [15], the extreme nature of the profession also affects the life expectancy of a person [22]. A relationship was also found between the rate of biological aging and retirement stress, a person's attitude to pension reform [23]. However, the issue of the distribution of biomarkers of aging (within biological age) in all professional types remains insufficiently studied.

\section{Materials and Methods}

The aim of the study was to study the distribution of biomarkers of aging (within biological age) in representatives of various psychological types of people.

Hypothesis: the rate of individual aging of an adult is influenced by the type of his personality: the profession he was engaged throughout life, the presence of functional asymmetry (right-handed/left-handed), body type, features of emotionality and attitudes towards other people.

Methods.

- Measurement of biomarkers of aging.

1. Diastolic blood pressure 
2. Pulse pressure

3. Body weight. In kilograms.

4. Static balancing (SB). Objective biomarker of aging. Stand on the left leg with closed eyes (in seconds).

5. Shtange test. The duration of holding the breath after a deep inhalation in seconds.

6. Subjective assessment of diseases (S.A.D). Subjective biomarker of aging. It is a questionnaire listing the main age-related health disorders. The more points a person gains, the higher the level of diseases.

- Frailty Index according to V. P. Voitenko.

All biomarkers highlighted above are included in the Russian Frailty Index according to V. P. Voitenko. This technique was developed at the Research Institute of Gerontology of the Academy of Medical Sciences of the USSR and is actively used in Russia. The method has been tested and validated in Russia. It has been shown that the biological age determined by this method correlates with the health of the cardiovascular system and life expectancy [21].

In accordance with this method, biological age is assessed using formulas.

For men:

Frailty index $($ Biological age $)=27.0+0.22 *($ systolic blood pressure $)-0.15^{*}$ (breath holding after inhalation) $+0.72 *$ (subjective self-assessment of diseases) $-\mathrm{O}, 15^{*}$ (statistical balancing).

For women:

Frailty index $($ Biological age $)=-1.46+0.42 *$ (pulse blood pressure $)+0.25^{*}$ (body weight) $+0.70 * \mathrm{SAD}$ (subjective self-assessment of diseases) $-0.14 * \mathrm{SB}$ (statistical balance).

- The relative ageing index (biological age - expected biological age).

\subsection{Generalized biomarker of aging}

Allows assessing how much a person is older than the statistical age norm in terms of his health. Negative values indicate a person's individual youth, while positive values indicate individual aging relative to statistical norms.

The expected biological age (EBA) included in this index was calculated in accordance with the formulas of Dr Voitenko. For men: EBA $=0.629 \times$ Calendar Age $(C A)+18.56$; for women: $\mathrm{EBA}=0.581 \times \mathrm{CA}+17.24$. To develop this indicator, V. P. Voitenko examined large groups of healthy people of various age and, using regression equations, derived a formula for estimating the EBA indicator of a healthy person.

1. Professional type assessment. The professional type was determined according to the typology of John Holland [24]. The following types were distinguished: Realistic type, Investigative type, Artistic type, Social type, Enterprising type, Conventional type. The types were distinguished on the basis of the professional activity that a person was engaged throughout his life.

2. Assessment of the left-right asymmetry in the dominant hand. The following types were distinguished: right-handers, ambidexters (including retrained left-handers), left-handers.

3. Assessment of body type. They were distinguished on the basis of anthropometric data. The following types were distinguished: asthenic, pyknic, athletic and harmonious (indefinite).

4. Assessment of the type of relationship with the world. The subjects were offered a game based on the Prisoner's Dilemma [25]. Four situations were proposed, in each of which the subject could choose the option of cooperation with another person or rivalry. The following types were distinguished: competitive (who chose the style of rivalry in 3-4 game situations), compromise (combining styles of cooperation and rivalry), cooperating (who chose the style of cooperation in all 4 situations). 
5. Assessment of the type of emotionality. We used the Rusalov test for diagnostics of emotionality, which is well-known in Russia. Three types of emotionality were distinguished: Psychomotor emotionality (experiences associated with failures and achievements in physical labor), intellectual (experiences associated with failures and achievements in mental work), communicative emotionality (experiences associated with failures and achievements in communication) (https://mylektsii.ru/5-42970.html)

6. Methods of mathematical statistics. One-factor Anova (Statistika-12) was used to assess the influence of the personality type on the distribution of biomarkers of aging. The dependent variable was the biomarkers of aging, and the independent variable was the types of individuality. To compare different types with each other, we used the Fisher LSD test, which is part of the analysis of variance.

\subsection{Test subjects}

987 people (of which 575 are women) aged 35-70. The sample was taken from different regions of Russia (Moscow, Moscow region, North Ossetia, Bashkortostan). The sample was organized according to the territorial principle - adults living in a territorial area assigned to a medical or educational institution were examined.

The sample was distributed by psychotype.

By professional type: Realistic type - 389 people, Investigative type - 27 people, Social type - 310 people, Conventional type - 190 people, Enterprising type - 59 people, Artistic type - 12 people.

By types of right-left-sided asymmetry: right-handers - 881 people, ambidexters - 50 people, left-handers - 43 people.

By physique: asthenic - 128 people, pyknic - 283 people, athletic - 127 people, and harmonious - 436 people.

By the type of relationships with other people: rival - 142 people, compromise - 437 people, cooperating - 408 people.

By the type of emotionality: Psychomotor emotionality - 327 people, intellectual emotionality - 213 people, communicative emotionality - 429 people.

\section{Results}

At the first stage, we studied the distribution of biomarkers of aging in representatives of various professional types (Table 1).

Table 1. Distribution of biomarkers of aging in professional types.

\begin{tabular}{|c|c|c|c|c|c|c|c|c|}
\hline & $\mathbf{1}$ & $\mathbf{2}$ & $\mathbf{3}$ & $\mathbf{4}$ & $\mathbf{5}$ & $\mathbf{6}$ & & \\
\hline $\begin{array}{c}\text { Biomarke } \\
\text { rs of aging }\end{array}$ & $\begin{array}{c}\text { Realisti } \\
\mathrm{c} \text { type }\end{array}$ & $\begin{array}{c}\text { Investigati } \\
\text { ve type }\end{array}$ & $\begin{array}{c}\text { Socia } \\
1 \\
\text { type }\end{array}$ & $\begin{array}{c}\text { Convention } \\
\text { al type }\end{array}$ & $\begin{array}{c}\text { Enterprisi } \\
\text { ng type }\end{array}$ & $\begin{array}{c}\text { Artisti } \\
\mathrm{c} \text { type }\end{array}$ & $\mathrm{F}$ & $\mathrm{p}$ \\
\hline $\begin{array}{c}\text { relative } \\
\text { ageing } \\
\text { index }\end{array}$ & $-0.17^{26}$ & $-6.37^{1345}$ & $\begin{array}{c}0.64^{2} \\
6\end{array}$ & $0.05^{26}$ & $0.52^{26}$ & $\begin{array}{c}6.7^{1345} \\
\begin{array}{c}13.127 \\
3\end{array}\end{array}$ & $\begin{array}{c}\mathrm{p}=.0083 \\
0\end{array}$ \\
\hline SB & $29^{345}$ & 27 & $17^{15}$ & $13^{15}$ & $40^{134}$ & 31 & $\begin{array}{c}\mathrm{F}(5.98 \\
1)\end{array}$ & $\begin{array}{c}\mathrm{p}=.0000 \\
0\end{array}$ \\
\hline
\end{tabular}




\begin{tabular}{|l|l|l|l|l|l|l|c|l|}
\hline & & & & & & & $\begin{array}{c}=10.18 \\
7\end{array}$ & \\
\hline S.A.D & $14^{245}$ & $8^{1346}$ & $16^{245}$ & $19^{1235}$ & $9^{1346}$ & $15^{25}$ & $\begin{array}{c}\mathrm{F}(5.98 \\
1) \\
22.89 \\
9\end{array}$ & $\begin{array}{c}\mathrm{p}=0.000 \\
0\end{array}$ \\
\hline
\end{tabular}

Note: ${ }^{123456}$ - differences with the group under this number are reliable with $\mathrm{p}<0.05$.

Relative ageing index - biological age - expected biological age.

SB - static balancing (in seconds).

S.A.D - subjective assessment of diseases (in points).

As can be seen from the table, the smallest values of the Relative aging index are for the representatives of the Investigative type and Artistic type of professions. Their biological age is on average 6 years less than the statistical norm. However, in terms of the duration of static balancing, representatives of the Enterprising type are superior to all, they also have the lowest self-assessment of diseases. Also, representatives of the Investigative type have a low self-assessment of diseases.

At the second stage, we studied the distribution of biomarkers of aging in individuals with different forms of functional asymmetry, differing in the dominant hand (Table 2).

Table 2. Distribution of biomarkers of aging in types of right-left asymmetry.

\begin{tabular}{|c|c|c|c|c|c|}
\hline & $\mathbf{1}$ & $\mathbf{2}$ & $\mathbf{3}$ & & \\
\hline $\begin{array}{c}\text { Biomarkers } \\
\text { of aging }\end{array}$ & left-handers & ambidexters & right-handed & $\mathrm{F}$ & $\mathrm{p}$ \\
\hline $\begin{array}{c}\text { relative } \\
\text { ageing index }\end{array}$ & $0.53^{2}$ & $-3.97^{13}$ & $-0.25^{2}$ & $\begin{array}{c}\mathrm{F}(2.971) \\
=3.4060\end{array}$ & $\mathrm{p}=.03357$ \\
\hline SB & $37^{3}$ & $40^{3}$ & $21^{12}$ & $\begin{array}{c}\mathrm{F}(2.971) \\
=10.852\end{array}$ & $\mathrm{p}=.00002$ \\
\hline S.A.D & $12^{3}$ & $10^{3}$ & $16^{12}$ & $\begin{array}{c}\mathrm{F}(2.971) \\
=18.322\end{array}$ & $\mathrm{p}=.00000$ \\
\hline
\end{tabular}

Note: ${ }^{123}$ - differences with the group under this number are reliable with $\mathrm{p}<0.05$.

Relative ageing index - biological age - expected biological age.

SB - static balancing (in seconds).

S.A.D - subjective assessment of diseases (in points).

As can be seen from the table, the best values of the Relative aging index are in ambidexters, where we included persons who use both hands equally well and retrained lefthanders. Their biological age is on average 4 years lower than the statistical norm. They also have the best static balancing scores and the lowest scores for self-assessment of diseases.

At the third stage, we studied the distribution of biomarkers of aging in subjects with different body types (Table 3 ).

Table 3. Distribution of biomarkers of aging in subjects with different body types.

\begin{tabular}{|c|c|c|c|c|c|c|}
\hline & $\mathbf{1}$ & $\mathbf{2}$ & $\mathbf{3}$ & $\mathbf{4}$ & & \\
\hline $\begin{array}{c}\text { Biomarkers of } \\
\text { aging }\end{array}$ & asthenic & pyknic & athletic & harmonious & $\mathrm{F}$ & $\mathrm{p}$ \\
\hline
\end{tabular}




\begin{tabular}{|c|c|c|c|c|c|c|}
\hline $\begin{array}{c}\text { relative ageing } \\
\text { index }\end{array}$ & $-3.08^{24}$ & $2.64^{134}$ & $-4.78^{24}$ & $-0.32^{123}$ & $\begin{array}{c}\mathrm{F}(3.970) \\
=20.655\end{array}$ & $\mathrm{p}=.00000$ \\
\hline SB & $20^{3}$ & $17^{3}$ & $45^{124}$ & $19^{3}$ & $\begin{array}{c}\mathrm{F}(3.970) \\
=20.769\end{array}$ & $\mathrm{p}=.00000$ \\
\hline S.A.D & $15^{3}$ & $17^{3}$ & $10^{124}$ & $16^{3}$ & $\begin{array}{c}\mathrm{F}(3.970) \\
=24.146\end{array}$ & $\mathrm{p}=.00000$ \\
\hline
\end{tabular}

Note: ${ }^{1234}$ - differences with the group under this number are reliable with $\mathrm{p}<0.05$.

Relative ageing index - biological age - expected biological age.

SB - static balancing (in seconds).

S.A.D - subjective assessment of diseases (in points).

As can be seen from the table, the best values of the Relative aging index are among representatives of athletic and asthenic body types. In athletes, the biological age is on average 4.8 years less than the statistical norm, and in asthenic type, it is lower by 3 years. The athletic type also has the highest static balancing rate and the lowest score for subjective assessment of diseases.

At the fourth stage, we studied the distribution of biomarkers of aging in subjects who differ in the style of interaction with other people (Table 4).

Table 4. Distribution of biomarkers of aging by styles of interaction with other people.

\begin{tabular}{|c|c|c|c|c|c|}
\hline $\begin{array}{c}\text { Biomarkers } \\
\text { of aging }\end{array}$ & Rival & Compromise & Cooperative & $\mathrm{F}$ & $\mathrm{p}$ \\
\hline $\begin{array}{c}\text { relative } \\
\text { ageing index }\end{array}$ & -0.62 & $1.0^{3}$ & $-2.0^{2}$ & $\begin{array}{r}\mathrm{F}(2.984) \\
=9.6745\end{array}$ & $\mathrm{p}=.00007$ \\
\hline SB & 26 & 20 & 25 & $\begin{array}{c}\mathrm{F}(2.984) \\
=2.1194\end{array}$ & $\mathrm{p}=.12065$ \\
\hline S.A.D & 14 & 16 & 15 & $\begin{array}{r}\mathrm{F}(2.984) \\
=2.9888\end{array}$ & $\mathrm{p}=.05080$ \\
\hline
\end{tabular}

Note: ${ }^{123}$ - differences with the group under this number are reliable with $\mathrm{p}<0.05$.

Relative ageing index - biological age - expected biological age.

SB - static balancing (in seconds).

S.A.D - subjective assessment of diseases (in points).

As can be seen from the table, the best values of the Relative aging index were found in people who preferred the style of cooperation in communication. Their biological age is on average 2 years less than the statistical norm. However, neither in the time of static balancing, nor in the self-assessment of diseases, they do not differ from the subjects with other styles of interaction (with rival and with compromise).

At the fifth stage, we studied the distribution of biomarkers of aging in subjects with different types of emotionality (Table 5).

Table 5. Distribution of biomarkers of aging by emotionality types.

\begin{tabular}{|c|c|c|c|c|c|}
\hline & $\mathbf{1}$ & $\mathbf{2}$ & $\mathbf{3}$ & & \\
\hline $\begin{array}{c}\text { Biomarkers of } \\
\text { aging }\end{array}$ & Psychomotor & Intellectual & Communicative & $\mathrm{F}$ & $\mathrm{p}$ \\
\hline
\end{tabular}




\begin{tabular}{|c|c|c|c|c|c|}
\hline $\begin{array}{c}\text { relative ageing } \\
\text { index }\end{array}$ & $0.43^{3}$ & $0.30^{3}$ & $-1.38^{12}$ & $\begin{array}{c}\mathrm{F}(2.966) \\
=3.6126\end{array}$ & $\mathrm{p}=.02735$ \\
\hline SB & $23^{3}$ & $16^{3}$ & $27^{12}$ & $\begin{array}{r}\mathrm{F}(2.966) \\
=7.1542\end{array}$ & $\mathrm{p}=.00082$ \\
\hline S.A.D & $16^{3}$ & $16^{3}$ & $14^{12}$ & $\begin{array}{c}\mathrm{F}(2.966) \\
=4.1224\end{array}$ & $\mathrm{p}=.01649$ \\
\hline
\end{tabular}

Note: ${ }^{123}$ - differences with the group under this number are reliable with $\mathrm{p}<0.05$.

Relative ageing index - biological age - expected biological age.

SB - static balancing (in seconds).

S.A.D - subjective assessment of diseases (in points).

As can be seen from the table, the best values of the Relative aging index are among people who prefer a collaborative style of interaction. Their biological age is on average 1.4 years less than the statistical norm, while they also have the highest static balancing rate and the lowest subjective assessment of diseases.

\section{Discussion}

Our research has confirmed this hypothesis. Indeed, a person's belonging to a certain type of personality affects the rate of his individual aging. This applies to all types we studied. In the aspect of professional activity, it was shown that the lowest rate of aging in Russia is observed in people of intellectual and creative professions. Their biological age is lower than the calendar and expected biological age. Representatives of other professional types do not differ in their aging rate from each other. However, if you look at the dynamics of subjective and objective components of biological age, you can try to assess the possible mechanism of antiaging. According to the objective biomarker - the time of statistical balancing on the left leg - the representatives of the Enterprise type have the highest indicator - managers and businessmen; in second place, there are representatives of the Realistic type - this includes working specialties and those who are engaged in official activities (police, security, etc.). The worst indicator belongs to people of "sedentary work" - representatives of office professions. In other words, representatives of intellectual and creative professions achieve high values of antiaging not because they retain the ability to maintain balance, but due to some other mechanisms. It should be noted that the time of static balancing depends on the safety of the balance system and the musculoskeletal system, on the one hand, and persistence and perseverance, on the other. Apparently, representatives of the Enterprise type get high values for this indicator precisely due to perseverance and persistence. According to the biomarker "subjective assessment of diseases", representatives of the Enterprising type, as well as representatives of the Investigative type, also demonstrate the best result - they note the least number of diseases. The worst result still belongs to representatives of the Conventional type. However, despite such good indicators of biomarkers that depend on selfassessment or personal efforts, according to the generalized frailty index, representatives of the Enterprising type have a high aging rate, most likely due to the deterioration of the cardiovascular and respiratory systems included in the biological age formula. This coincides with the classic studies of M. Friedman and R. Rosenman, who showed the connection between type A behavior (which is expressed in representatives of the Enterprise type) and the risk of cardiovascular disease [10].

In general, our data confirm the previously obtained results of other researchers. For example, according to a study by Anisimov and Zharinov, who studied the average age at death (AAD) of 49064 well-known representatives of the research and creative type of professions: from the 1 st century to the Christian era to the end of the 20th century, it was 
shown that $\mathrm{AAD}$ of representatives for the majority of these professions is higher than the average for the sample. The first five places in terms of life expectancy among men are occupied by Nobel laureates (78.8 years), scientists (72.7 years), corresponding members (71.7 years), conductors (71.1 years), and scientists (71, 0 years). Among women, the top five places for AAD are held by conductors (83.2 years), harpers (80.9 years), academicians (80.3 years), harpsichords (79.1 years), and violinists (78.2 years) [26].

The study of biomarkers of aging in individuals with different types of functional asymmetry showed that ambidexters and retrained left-handers are in the best conditions; their rate of individual aging is the lowest, the indicators of statistical balancing are the highest, and the self-assessment of age-related diseases is the lowest. Apparently, the combination of the activity of the right and left hemispheres, right and left hands have a beneficial effect on the entire body and help to slow down individual aging in many indicators. This is new data that we have not yet found confirmation by other researchers.

With regard to the distribution of biomarkers of aging in people with different body types, our results were expected. They showed that the highest rate of aging is in representatives of the pyknic body type, who, as a rule, have overweight, which interferes with static balancing and causes many age-related diseases. Many researchers have considered obesity and overweight as a particular health risk; recent studies using epigenetic biomarkers of age have shown that obesity increases the risk of death from many causes, and also affects the rate of relative aging of the body, accelerating it [1].

In our studies, the best antiaging indicators were found in representatives of the athletic and asthenic types. At the same time, the athletic type also demonstrates good physical data - it has the highest static balancing rate and good subjective health - it has the least of all agerelated ailments. This data explains the low rate of aging of the athletic type. As for the asthenic type, its subjective health and physical capabilities are the same as in other types, apparently, he achieves his relative youth through other biomarkers (possibly, low body weight and better performance of the cardiovascular system).

As our study has shown, the rate of individual aging is also influenced by the style of interaction with other people assumed by a person. People who prefer the style of cooperation turn out to be in a better position. In interpersonal interaction, they demonstrate altruistic motives, show concern for other people, and take into account the general benefits of their activities. Such people have the lowest rate of individual aging. And what is interesting is that this rate of aging is determined by other biomarkers than those studied in our study, because static balancing and subjective assessment of diseases do not differ from other types in them. Maybe the altruistic style of interaction promotes better functioning of the cardiovascular and respiratory systems, and also contributes to the normalization of metabolism (absence of excess weight). Our results coincide with the data of other researchers, for example, with the results of M. Poulin and his colleagues, who observed 846 subjects for 5 years: those who actively helped others during the previous year were less likely to die than those who did not provide assistance. The authors explain it by the fact that altruistic behavior creates a buffer in the human psyche, as if accumulating energy, thereby protecting it from the action of negative factors, and this leads to a decrease in the likelihood of death [27].

The type of emotionality also influences the distribution of biomarkers. The best rate of individual aging is found in people with communicative emotionality. This is also confirmed by the dynamics of the objective and subjective biomarkers of aging - they have better indicators of static balancing and lower estimates of age-related diseases. Psychologically, such people are very sensitive to social things, they are more likely to experience failures in communication than errors of an intellectual plan and difficulties in labor activity. And vice versa, they are more pleased with the success in communication, the establishment of relationships, mutual "stroking". This makes them more tactful and delicate in the field of 
communication. But people with a predominance of intellectual and psychomotor emotionality do not differ from each other in terms of biomarkers of aging.

\section{Conclusion}

As our study has shown, a person's belonging to a certain type of personality affects the appearance of biomarkets of aging in him and his frailty index (biological age). To assess the frailty index, we used the well-known Russian method of Dr. Voitenko for determining the biological age, which includes subjective and objective biomarkers of aging. The intensity of biomarkers of aging is influenced by the following personality factors: professional activity performed during the course of life, features of the functional asymmetry of the hemispheres, body type, peculiarities of the emotional sphere, and the predominant style of relationships with other people. The best indicators of relative aging (lower frailty index) are observed in representatives of the Artistic type and Investigative type of professions, and according to the objective biomarker of aging (duration of static balancing), representatives of the Enterprise type have the best indicators, they also assess their health status higher. According to functional asymmetry determined by the dominant hand, the best values of the frailty index are observed in ambidexters and retrained left-handers, and they also have the best values of subjective and objective biomarkers of aging. In terms of physique, a lower frailty index is observed in representatives of the asthenic and athletic type, and in representatives of the pyknic type, the biological age, on the contrary, often exceeds the calendar and expected biological age, they withstand the least time of static balancing and assess their health worse than other types.

Among the emotional types, a lower frailty index is observed in people with communicative emotionality, for whom relations with other people are very important, they can hardly tolerate bad luck in communication and are happier with achievements. In terms of self-assessment of health and the duration of static balancing, they also show the best results in comparison with other people. The rate of individual aging is also influenced by the style of a person's relationship with other people. People who prefer a collaborative style and demonstrate an altruistic relationship strategy age more slowly than those who prefer a compromise communication style.

It can be concluded that the lifestyle, attitude towards the world and other people, as well as the phenotypic characteristics of a person affect his biological age and the intensity of his biomarkers of aging.

\section{Acknowledgements}

This work was supported by Russian Science Foundation, No. 19-18-00058

\section{References}

1. A. Quach, M.E. Levine, T. Tanaka et al., AGING 9(2), 419-446 (2017) https://doi.org/10.18632/aging.101168

2. S.D. Searle, A. Mitnitski, E.A. Gahbauer, T.M. Gill, K. Rockwood, BMC Geriatrics 8(1), 24 (2008) doi:10.1186/1471-2318-8-24

3. T. Berezina, Voprosy Psikhologii 2017(2), 79-88 http://www.scopus.com/inward/record.url?eid=2-s2.085026631075\&partnerID=MN8TOARS 
4. S.N. Burke, E.C. Mormino, E.J. Rogalski, C.H. Kawas, R.J. Willis, D.C. Park, Neurobiology of Aging 83, 140-144 (2019) https://doi.org/10.1016/j.neurobiolaging.2019.03.023

5. P.M. Engelfriet, E.H. Jansen, H.S. Picavet, M.E. Dolle, Epidemiol Rev. 35, 132 (2013) doi: 10.1093/epirev/mxs011

6. C. Lopez-Otin, M.A. Blasco, L. Partridge, M. Serrano, G. Kroemer, Cell. 153, 1194 1217 (2013) doi:10.1016/j.cell.2013.05.039

7. T.E. Johnson, Exp Gerontol. 41, 1243-1246 (2006) doi: 10.1016/j.exger.2006.09.006

8. J. Lara, R. Cooper, J. Nissan, et al., BMC Med. 13, 222 (2015) doi: 10.1186/s12916015-0470-9

9. K.H. Wagner, D. Cameron-Smith, B. Wessner et al., Nutrients 8(6), pii: E338 (2016) doi: 10.3390/nu8060338

10. O. Stavrova, D. Ehlebracht, Eur. J. Pers. 33, 52-71 (2019) https://doi.org/10.1002/per.2183

11. I. Niedhammer, J. Chastang, D. Levy, et al., Int. Arch. Occup. Environ. Health 82, 8797 (2008) https://doi.org/10.1007/s00420-008-0311-7

12. J. Siegrist, N. Wege, F. Pühlhofer et al., Int. Arch. Occup. Environ. Health 82, 1005 (2009) https://doi.org/10.1007/s00420-008-0384-3

13. M. Gilbert-Ouimet, X. Trudel, C. Brisson, A. Milot, M. Vezina, Scand J Work Environ Health 40(2), 109-132 (2014) doi:10.5271/sjweh.3390.

14. Y. Stephan, A.R. Sutin, M. Luchetti, A. Terracciano, The Journals of Gerontology B72(6), 966-973 (2017) https://doi.org/10.1093/geronb/gbw085

15. T.N. Berezina, N.N. Rybtsova, S.A. Rybtsov, G.V. Fatianov, Journal of Modern Foreign Psychology 9(1), 8-21 (2020) doi:10.17759/jmfp.2020090101

16. P. Coenen, M.A. Huysmans, A. Holtermann et al., Br J Sports Med. 52(20), 1320-1326 (2018) https://doi.org/10.1136/bjsports-2017-098540

17. T.N. Berezina, E.I. Mansurov, Voprosy Psikhologii 3, 73-83 (2015) http://www.scopus.com/inward/record.url?eid=2-s2.0-84941642871\&partnerID= MN8TOARS

18. S.P. Tsai et al., British Medical Journal 331, 995-997 (2005) DOI:10.1136/bmj.38586.448704.E0

19. A. Mitnitski, J. Collerton, C. Martin-Ruiz, et al., BMC Medicine 13(1), 161 (2015) doi:10.1186/s12916-015-0400-x

20. T. Berezina, K. Buzanov, A.M. Zinatullina, A.A. Kalaeva, V.P. Melnik, Religación. Revista De Ciencias Sociales Y Humanidades 4(18), 192-198 (2019) http://revista.religacion.com/index.php/religacion/article/view/419

21. V.P. Voitenko, A.V. Tokar, Exp. Aging. Res. 9(4), 239-244 (1983) https://doi.org/10.1080/03610738308258458

22. T.N. Berezina, V.I. Ekimova, A.V. Kokurin, E.A. Orlova, Psikhologicheskii Zhurnal 39(3), 70-78 (2018) DOI: 10.7868 / S0205959218030066

23. T.N. Berezina, S.A. Stelmakh, E.V. Dergacheva, Psychologist 5, 11-26 (2019) DOI: 10.25136/2409-8701.2019.5.31159

24. M.M. Nauta, J. Couns. Psychol. 57(1), 11-22 (2010) DOI: https://doi.org/10.1037/a0018213 
25. S. Kopelman, Negotiation and Conflict Management Research (NCMR) 13(1), 6084 (2020) https://doi.org/10.1111/ncmr.12172

26. V.N. Anisimov, G.M. Zharinov, Adv. Gerontol 4, 83-94 (2014) https://doi.org/10.1134/S2079057014020027

27. M.J. Poulin, S.L. Brown, P.A. Ubel, D.M. Smith, A. Jankovic, K.M. Langa, Psychology and Aging 25, 108-117 (2010) doi: 10.1037/a0018064, 